\title{
Brown-McLean syndrome: the role of iridodonesis
}

This article was published in the following Dove Press journal:

Clinical Ophthalmology

15 April 2016

Number of times this article has been viewed

\author{
Yanin Suwan \\ Chaiwat Teekhasaenee \\ Kaevalin Lekhanont \\ Wasu Supakontanasan \\ Department of Ophthalmology, \\ Faculty of Medicine, Ramathibodi \\ Hospital, Mahidol University, \\ Bangkok, Thailand
}

Purpose: The aim of this study was to report a case series of Brown-McLean syndrome (BMS). Methods: The charts of 28 patients with BMS at Ramathibodi and Rutnin Hospital from 1981 to 2015 were reviewed.

Results: BMS is a rare condition with corneal edema involving the peripheral cornea with orange-brown pigment deposition underlying the edematous area. The edema typically starts inferiorly and advances circumferentially to superior cornea. Central cornea remains clear in most patients. We report 28 patients with BMS that occurred either spontaneously or after various intraocular procedures. Ultrasound biomicroscopy was performed to demonstrate the iridocorneal relationship.

Conclusion: Iridocorneal relationship from the ultrasound biomicroscopy study in four patients did not support previous hypothesis about the role of iridodonesis impact on corneal endothelium. Patients with BMS can rarely progress to corneal decompensation; however, they should be periodically monitored and made aware of early clinical signs of their complications.

Keywords: Brown-McLean syndrome, peripheral corneal edema, marginal corneal edema, corneal decompensation

\section{Introduction}

Brown-McLean syndrome (BMS) was first described in 1969 as a delayed onset of peripheral corneal edema with underlying endothelial punctate orange pigmentation in long-standing pseudophakic patients by Brown and McLean. ${ }^{1}$ It has a benign clinical course with central cornea remaining clear for years. This condition most commonly occurs in aphakic eyes after intracapsular cataract extraction (ICCE). We report about BMS that occurred either spontaneously and after unusual intraocular procedures. In this case series, we report data of 28 patients with 35 affected eyes and study the clinical characteristics and natural course of this disease.

This study is one of the largest case series in BMS with longer follow-up. We also report ultrasound biomicroscopy (UBM) findings to demonstrate iridocorneal relationship, since iridodonesis was proposed to be responsible for the underlying pathogenesis of this condition. ${ }^{2-4}$

\section{Patients and methods}

We retrospectively reviewed the charts of 28 patients with BMS at Ramathibodi and Rutnin Hospital from 1981 to 2015. Demographic data such as age, sex, laterality, principal diagnosis, previous surgeries or inciting events, visual acuity, central and peripheral corneal status, presence of underlying pigment deposition, lenticular status, refractive status, and presence of corneal guttata were recorded. Corneal thickness, corneal endothelial cell count, degree of polymegathism, and pleomorphism were measured. Dynamic appearances of iridocorneal contact in various conditions were evaluated by UBM study. This study was approved by the Ramathibodi Hospital, hY
hereby accept the Terms. Non-commercial uses of the work are permitted without any further permission from Dove Medical Press Limited, provided the work is properly attributed. For permission for commercial use of this work, please see paragraphs 4.2 and 5 of our Terms (https://www.dovepress.com/terms.php). 
Mahidol University Ethic committee. Written, informed consent was obtained from all subjects and the study adhered to the tenets of the Declaration of Helsinki.

\section{Results}

The findings of 28 patients with 35 affected eyes are summarized in Table 1. There were 12 men and 16 women. The average age at the time of diagnosis was 45 years (range: 18-80 years). The longest follow-up time was 35 years. Almost all eyes (97\%) had circumferential peripheral corneal edema with one eye sparing the superior 10-2 o'clock position (Figure 1).

Four patients came for follow-up. Two eyes of two patients (cases 2 and 8) had average corneal endothelial density of $2,797 \mathrm{cell} / \mathrm{mm}^{3}$, which was slightly lower than that of the unaffected eyes $(P=0.1131)$. Few corneal guttata were detected in both affected and fellow eyes. Average central corneal thickness was $548 \mu \mathrm{m}$. Interestingly, 14 eyes of 12 patients ( $40 \%$ ) had high myopia and remained myopic, emmetropic, or mildly hyperopic despite the aphakic status, and 21 eyes of 17 patients were aphakic. Central cornea remained clear in most of the patients with the longest follow-up time of 35 years. Two of 35 eyes had progression to corneal decompensation, although maintaining the characteristic prominent edema in peripheral than in central cornea. Small punctate orange-brown pigmentation on the underlying endothelium of affected area was found in ten eyes. One patient $(2.86 \%)$ had calcium deposition in an edematous area.

Unusual underlying systemic and ocular diseases were also found: Marfan syndrome and familial iris hypoplasia.

ICCE was performed in eleven eyes before the diagnosis of BMS. Peripheral edema usually involves inferior 2-10 o'clock position regardless of the presence of superior surgical iridectomy (patient 15). Couching, the historical method for the treatment of blinding cataract, was performed in five eyes and was followed by secondary open-angle glaucoma in all cases. Other procedures such as lens aspiration and phacoemulsification, or even spontaneous lens dislocation, can lead to BMS in four eyes.

UBM revealed the absence of iridocorneal apposition in semi-upright position in four patients and remained unchanged with different room illuminations or accommodations (Figure 2).

\section{Discussion and review of literature}

BMS is a rare type of peripheral corneal edema. Table 2 is a summary of studies from the literature. The corneal edema

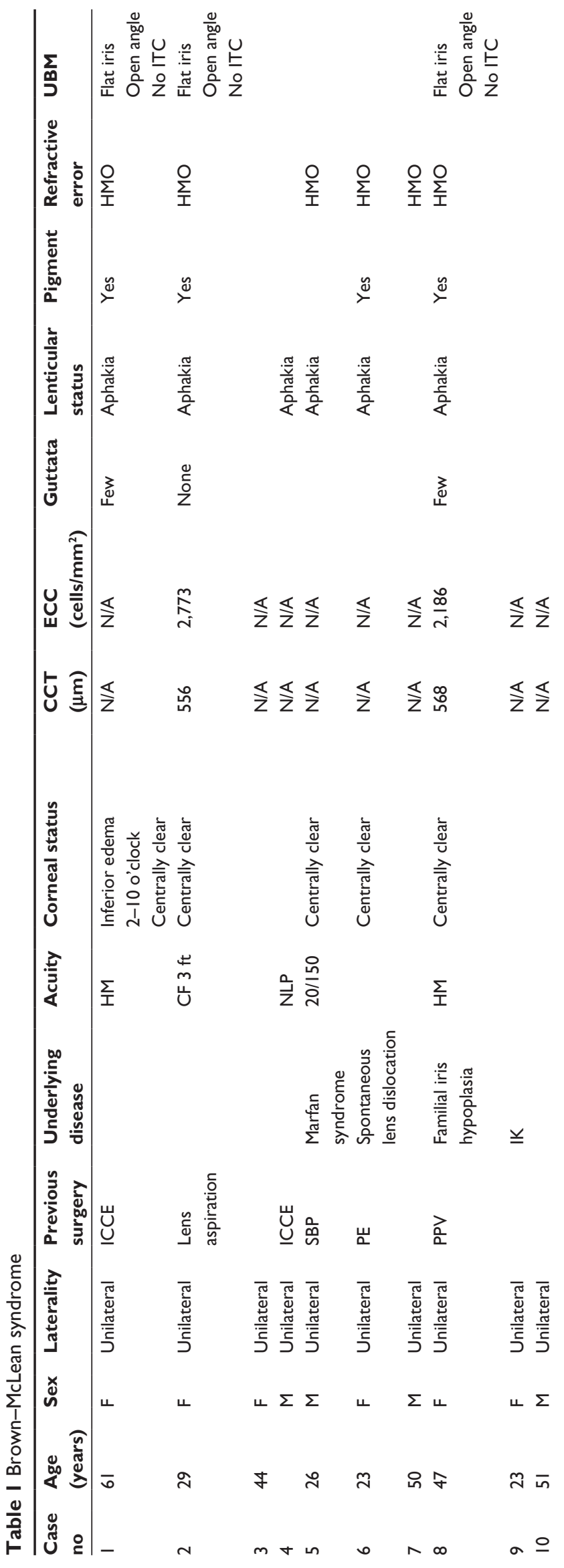




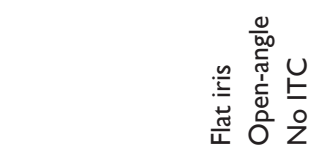<smiles>OC(O)OC1CCCCC1</smiles><smiles>COC1CC1</smiles>

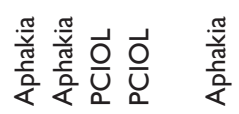

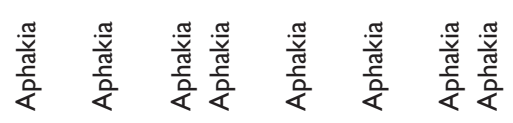

帝

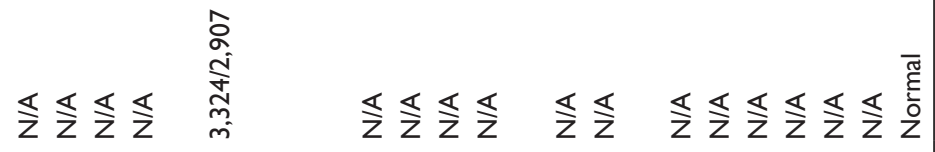

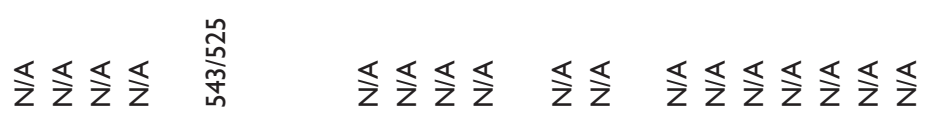

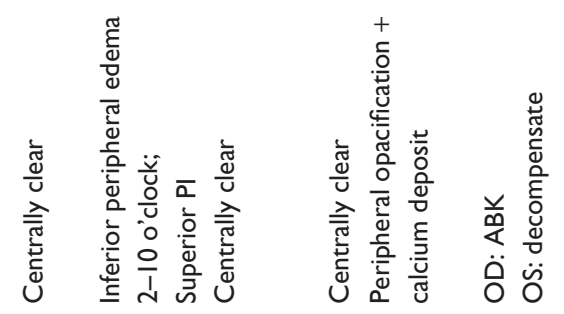

ัํำ

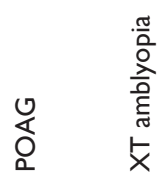

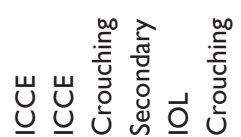

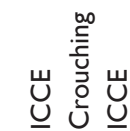

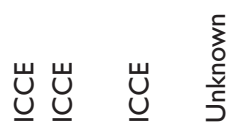

岂 $\underline{u}$
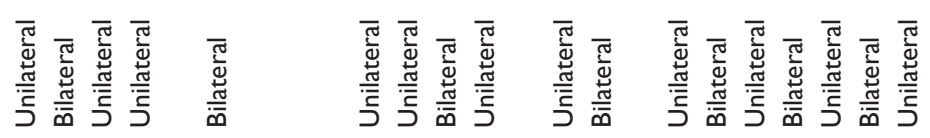

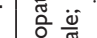

尊

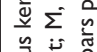

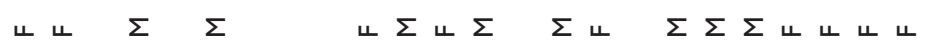

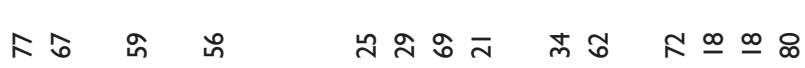

$=\simeq \underline{m} \pm \underline{\underline{n}}$ $\underline{0} \simeq \underline{\infty}$

구

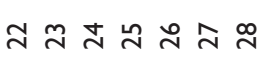




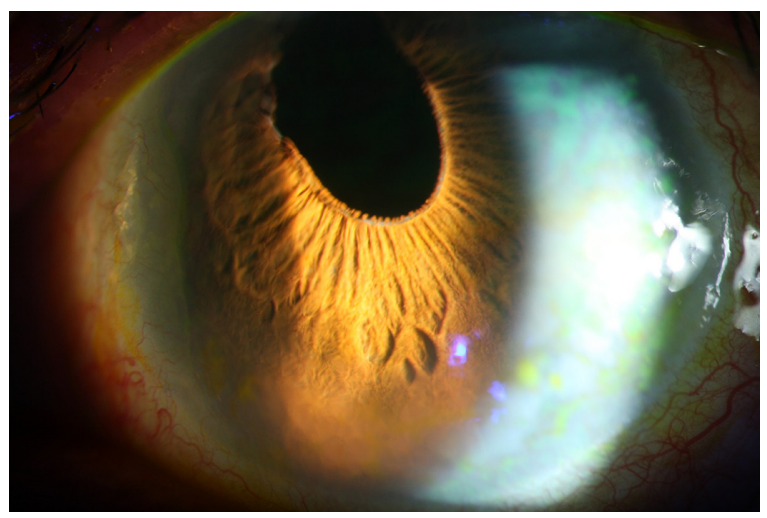

Figure I Clinical picture of Brown-McLean syndrome.

Note: This patient had inferior peripheral corneal edema sparing (10-2 o'clock position).

typically starts inferiorly, progresses circumferentially from the corner region corresponding to 6 o'clock position toward 3 o'clock and 9 o'clock positions simultaneously, and occupies peripheral cornea at $2.0-3.0 \mathrm{~mm}$ from the limbus. The edema often spares the superior cornea between the 10 o'clock and 2 o'clock position (horseshoe- or U-shaped configuration) and adjacent to cataract incision. Superior corneal sparing usually corresponds to surgical iridectomy location. We found classic inferior peripheral edema in three eyes (patients 1 and 15). Additionally, the edema is associated with a punctate orange-brown pigmentation deposition on the underlying endothelium of affected area, while the finding of cornea guttata is infrequent. The progression occurs over a time course, varying from months to several years. ${ }^{2}$ There is no associated corneal neovascularization or anterior chamber inflammation. Gonioscopy usually revealed opened anterior chamber angle. Peripheral anterior synechiae can be found from surgically induced inflammation.

The syndrome was first described in association with ICCE, but it has also been described after several types of lens surgery such as the extracapsular lens extraction,

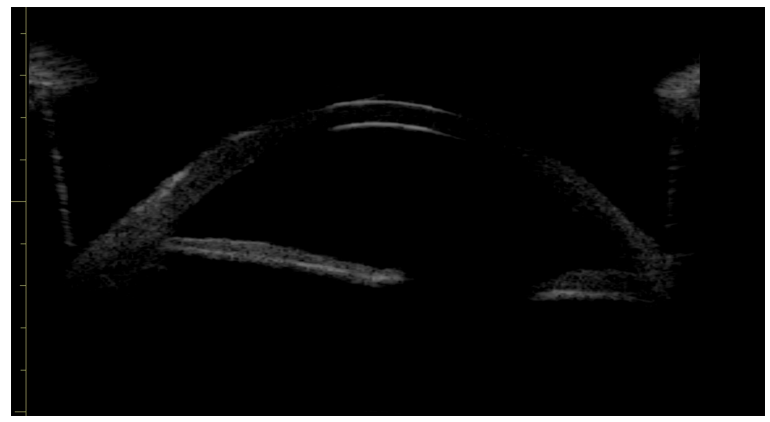

Figure 2 Ultrasound biomicroscopy showed absence of iridocorneal apposition.

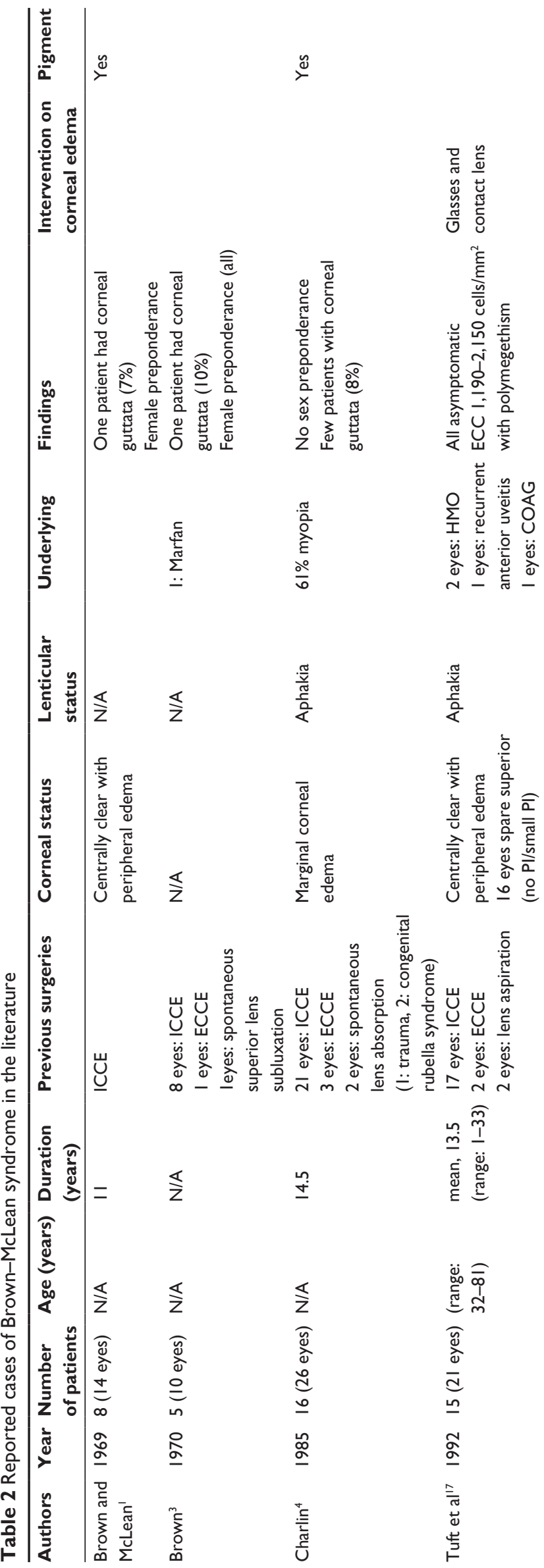




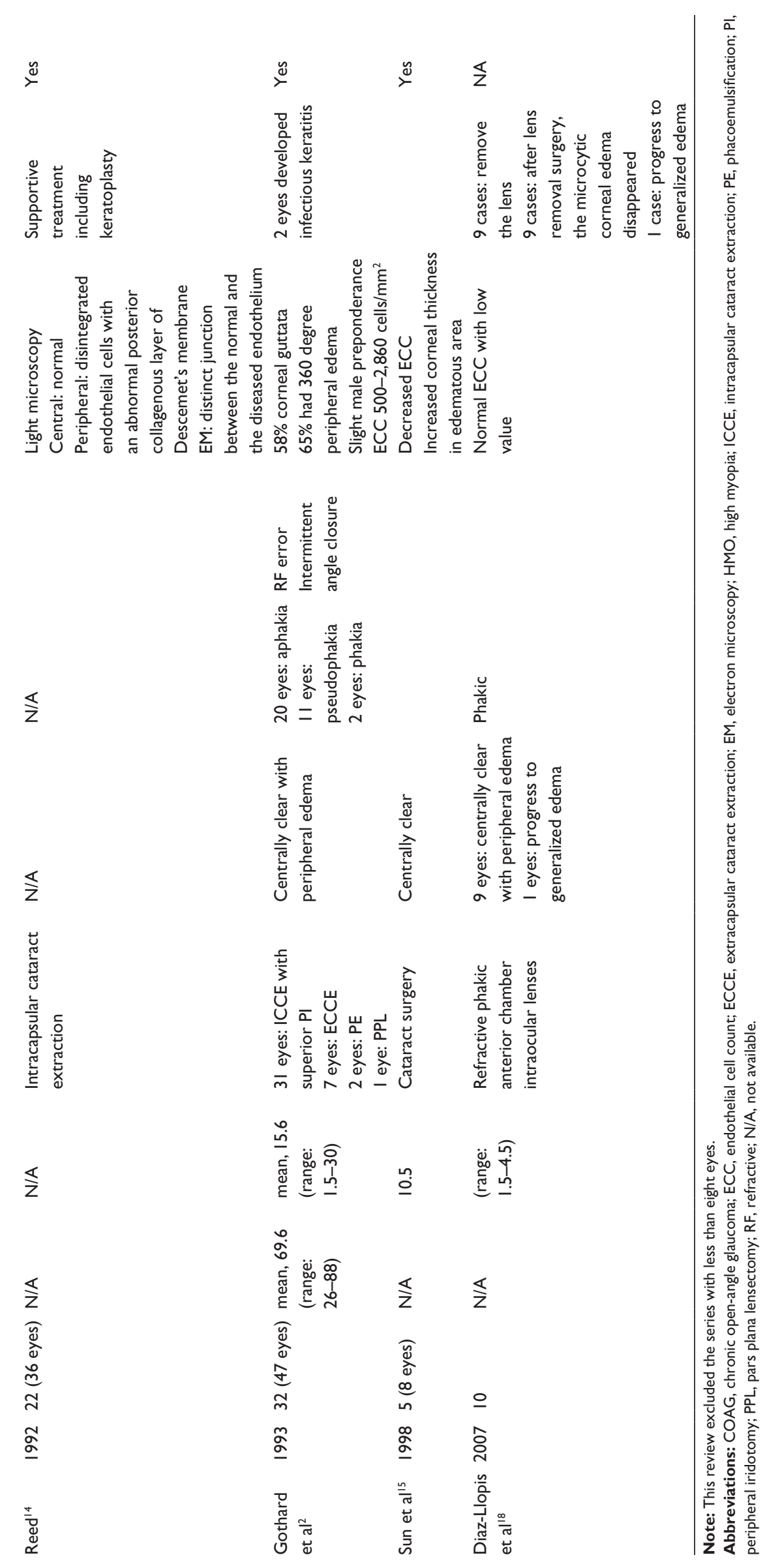


phacoemulsification, lensectomy, pars plana vitrectomy, anterior chamber intraocular lens implantation, penetrating keratoplasty, and in patients with no previous ocular surgery (eg, patients with spontaneous lens resorption with iridodonesis, lens subluxation or luxation [dislocation], phakic eye with intermittent angle closure, keratoconus, and myotonic dystrophy). ${ }^{1-10}$ In aphakic patients, iridodonesis had been suggested to be a cause of an intermittent abrasion of the endothelium..$^{2-4}$ The iridectomy may play a role in protecting corneal endothelium from mechanical trauma suggested by observation in characteristic superior corneal sparing. However, superior peripheral corneal edema despite large sectoral iridectomy had been reported. ${ }^{7}$ This finding was supported by our UBM study, which revealed the absence of iridocorneal touch with widely opened anterior chamber angle. BMS in phakic eye with spontaneous lens subluxation or spontaneous lens absorption was reported by Brown $^{3}$ and Charlin. ${ }^{4}$ In our series, one patient with familial iris hypoplasia developed BMS after bilateral spontaneous posterior lens dislocation. These eyes have a dynamic anterior chamber and iridodonesis similar to aphakic state. ${ }^{3,4,11}$ BMS in phakic eye with intermittent angle-closure glaucoma was reported; hence, increased intraocular pressure and inflammation may be responsible for recurrent endothelial trauma. ${ }^{2}$ Hara $^{5}$ reported one case of BMS with concurrent corneal endotheliitis that responded well to steroid therapy. Three members of an extended Pacific Islands family with bilateral spontaneous crystalline lens subluxation manifested with BMS were reported. ${ }^{9}$ Brown and McLean ${ }^{1}$ also described two eyes with BMS occurring in pairs of siblings, suggesting possible genetic predisposition and potential aggravation of the clinical presentation after surgery (two-hit theory). In our patients, couching was performed in five eyes with left aphakia, which produced similar results as ICCE, without intraocular lens implantation. High incidence of high myopia was also found in our series.

BMS usually spares central cornea for years (reported 4 weeks to 34 years) without a detectable decrease in corneal endothelial cell density or an increase in corneal thickness. ${ }^{2,7,9}$ The central corneal guttata is frequently seen in both affected and fellow eyes. These eyes may present with transient corneal edema but do not have permanent swelling. ${ }^{2,12}$ The confocal microscopy demonstrated healthy endothelium in BMS within the affected cornea. ${ }^{13}$ Conversely, Vote et al ${ }^{9}$ reported endothelial pigmentation, prominent nerves, and localized basal epithelial edema in peripheral cornea, while central cornea revealed large cellular structures with prominent nuclei. The light and electron microscopy revealed normal central cornea, while periphery showed disintegrated endothelial cells with an abnormal posterior collagenous layer of Descemet's membrane. Scanning electron microscopy also confirmed a distinct junction between the normal central endothelium and the diseased peripheral endothelium. ${ }^{14}$ The pathological reduction in the corneal endothelial cells with increased corneal thickness was described even though the central cells were normal. ${ }^{12,15}$

BMS usually presents with an uncomplicated clinical course. However, the clinical symptoms are vary greatly from asymptomatic peripheral corneal edema or mild foreign body sensation requiring only hypertonic saline and lubrication to severe pain due to ruptured bullae. Infectious corneal ulceration necessitating keratoplasty was reported. ${ }^{2,16}$ The management and visual rehabilitation of patients with BMS has been reported in the literature. Aphakic glasses correction or aphakic contact lens correction may be the alternative choices for visual rehabilitation in patients with good visual ability. However, anoxic stress associated with contact lens wear must be concerned in BMS patients who have susceptible corneal endothelial function. ${ }^{17}$ One patient in our series developed corneal decompensation but still showed characteristics of more prominent peripheral edema. ${ }^{18}$ Patients with BMS should be periodically monitored and made aware of early clinical signs of their complications.

As a result of retrospective nature in this rare peripheral corneal degeneration, there are several limitations in this study. The UBM analysis and specular microscopy were obtained in only four patients who came to follow-up since we did not have these instruments at the time of their initial presentation. Statistical analysis of risk factors could not be performed due to the limited data number.

\section{Conclusion}

In conclusion, BMS generally has an uncomplicated clinical course. However, complications may occur. We reported BMS after phacoemulsification and crouching. High myopia was found in $40 \%$ of all eyes. Further studies are needed to determine the pathogenesis of BMS and the role of high myopia in BMS development.

\section{Disclosure}

The authors report no conflicts of interest in this work.

\section{References}

1. Brown SI, McLean JM. Peripheral corneal edema after cataract extraction. A new clinical entity. Trans Am Acad Ophthalmol Otolaryngol. 1969;73(3):465-470.

2. Gothard TW, Hardten DR, Lane SS, Doughman DJ, Krachmer JH, Holland EJ. Clinical findings in Brown-McLean syndrome. Am J Ophthalmol. 1993;115(6):729-737. 
3. Brown SI. Peripheral corneal edema after cataract extraction. Am J Ophthalmol. 1970;70(3):326-328.

4. Charlin R. Peripheral corneal edema after cataract extraction. Am J Ophthalmol. 1985;99(3):298-303.

5. Hara T. Brown-Mclean syndrome associated with corneal endotheliitis in a pseudophakic eye. J Cataract Refract Surg. 1993;19(6):780-786.

6. Sugar A. Brown-McLean syndrome occurring in a corneal graft. Cornea. 1997;16(4):493-494.

7. Lim JI, Lam S, Sugar J. Brown-McLean syndrome. Arch Ophthalmol. 1991;109(1):22-23.

8. Rutzen AR, Deen A, Epstein AJ, Maldonado MJ, Hemady RK. Cataract surgery in a patient with Brown-McLean syndrome. J Cataract Refract Surg. 2001;27(8):1335-1337.

9. Vote BJ, Grupcheva CN, Ormonde SE, McGhee CN. In vivo confocal microstructural analysis and surgical management of Brown-Mclean syndrome associated with spontaneous crystalline lens luxation. J Cataract Refract Surg. 2003;29(3):614-618.

10. Jamil AZ, Rahman FU, Mirza KA, Iqbal W. Brown-McLean syndrome with keratoconus. J Coll Physicians Surg Pak. 2012;22(3): 179-181.

11. Charlin JF, Leluyer B, Brasseur G, Gruber D, Langlois J. Manifestations ophthalmologiques du syndrome de Bassen-Kornzweig: à propos d'un cas. [Ophthalmological manifestations of the Bassen-Kornzweig syndrome. Apropos of a case]. Bull Soc Ophtalmol Fr. 1985;85(1):11-18. French.
12. Martins EN, Alvarenga LS, Sousa LB, Orlando Filho VT, Gomes JA, de Freitas D. Anterior stromal puncture in Brown-McLean syndrome. J Cataract Refract Surg. 2004;30(7):1575-1577.

13. Lim LT, Tarafdar S, Collins CE, Ramamurthi S, Ramaesh K. Corneal endothelium in Brown-McLean syndrome: in-vivo confocal microscopy finding. Semin Ophthalmol. 2012;27(1-2):6-7.

14. Reed JW, Cain LR, Weaver RG, Oberfeld SM. Clinical and pathologic findings of aphakic peripheral corneal edema: Brown-McLean syndrome. Cornea. 1992;11(6):577-583.

15. Sun B, He Y, Zhong P, Wang R. [Peripheral corneal edema after cataract extraction]. Zhonghua Yan Ke Za Zhi. 1998;34(1):31-33. Chinese.

16. Moreno-Montanes J, Heras Mulero H, Rodriguez Conde RM. Variabilidad en la presentación del síndrome de brown-mclean. [Variability in the clinical presentation of the Brown-McLean syndrome]. Arch Soc Esp Oftalmol. 2004;79(6):299-301. Spanish.

17. Tuft SJ, Kerr Muir M, Sherrard ES, Buckley RJ. Peripheral corneal oedema following cataract extraction (Brown-McLean syndrome). Eye (Lond). 1992;6(pt 5):502-505.

18. Diaz-Llopis M, Garcia-Delpech S, Salom D, Udaondo P. Síndrome de Brown McLean y lentesrefractivas fáquicas de cámara anterior. [BrownMcLean syndrome and refractive phakic anterior chamber intraocular lenses]. Arch Soc Esp Oftalmol. 2007;82(12):737-738; author reply 8-9. Spanish.
Clinical Ophthalmology

\section{Publish your work in this journal}

Clinical Ophthalmology is an international, peer-reviewed journal covering all subspecialties within ophthalmology. Key topics include: Optometry; Visual science; Pharmacology and drug therapy in eye diseases; Basic Sciences; Primary and Secondary eye care; Patient Safety and Quality of Care Improvements. This journal is indexed on

Submit your manuscript here: http://www.dovepress.com/clinical-ophthalmology-journal

\section{Dovepress}

PubMed Central and CAS, and is the official journal of The Society of Clinical Ophthalmology (SCO). The manuscript management system is completely online and includes a very quick and fair peer-review system, which is all easy to use. Visit http://www.dovepress.com/ testimonials.php to read real quotes from published authors. 